\title{
SAMSARA OF ORGANIC CARBON
}

\author{
G. OURISSON \\ Laboratoire Associé au CNRS, Institut de Chimie, \\ Université Louis Pasteur, 67-Strasbourg, France
}

\begin{abstract}
A summary is presented of results obtained in the study of the organic matter contained in sediments. The evolution of this organic matter with age is discussed and its importance is emphasized for the understanding of processes occurring during diagenesis.
\end{abstract}

Organic Geochemistry is a recent Science: a well-documented review published in $1971^{1}$ lists some 300 references, half a dozen of which refer to papers published before 1945. Reviews ${ }^{1,2}$ and monographs ${ }^{3}$ have put on record present results and the philosophy of the work, so that we can dispense with a balanced presentation. I shall only give a personal description of our present approach to organic geochemical problems, with no attempt at showing how much more the field owes to other groups, such as those of Calvin, of Eglinton, and of many petroleum companies.

A global survey. Most argillaceous sediments studied so far contain some one or two per cent of organic carbon, be it a 'recent' sediment (say, from the Tertiary) or a 'very old' one (say, from the late Precambrian). A small mountain, $100 \mathrm{~m}$ high and $1 \times 1 \mathrm{~km}$ large, may contain some $4 \times 10^{6}$ tons of organic carbon in its minerals; on its surface, if densely covered by vegetation, it may bear only some $10^{3}$ tons of carbon in living trees, plants, animals and micro-organisms: less than one thousandth of its fossil carbon.

Such is the result of imperfect recycling. As organisms die, their organic matter decays, and their carbon returns to its most stable form in an oxygencontaining atmosphere: not dust, but carbon dioxide. This leads to the first, short lived, carbon cycle, followed in months or years. Recycling would be accomplished through re-use by photosynthesis, were it not for a flaw: this 'quick' cycle leaks into a second cycle, a long-lived one, followed in aeons. A small portion of organic matter escapes decay, and is buried with carbonates or silicates into sediments. It is preserved until orogenesis and erosion bring it back to the surface (Figure 1).

One estimates the total mass of organic carbon accumulated in sediments at some $6 \times 10^{15}$ tons - the mass of organic carbon present in living organisms at $3 \times 10^{12}$ tons. Organic Chemists should therefore mostly study rocks!

I shall restrict this report to our work on two lacustrine sediments, oil shales found near Strasbourg, in Messel (Germany) and Bouxwiller (France). 


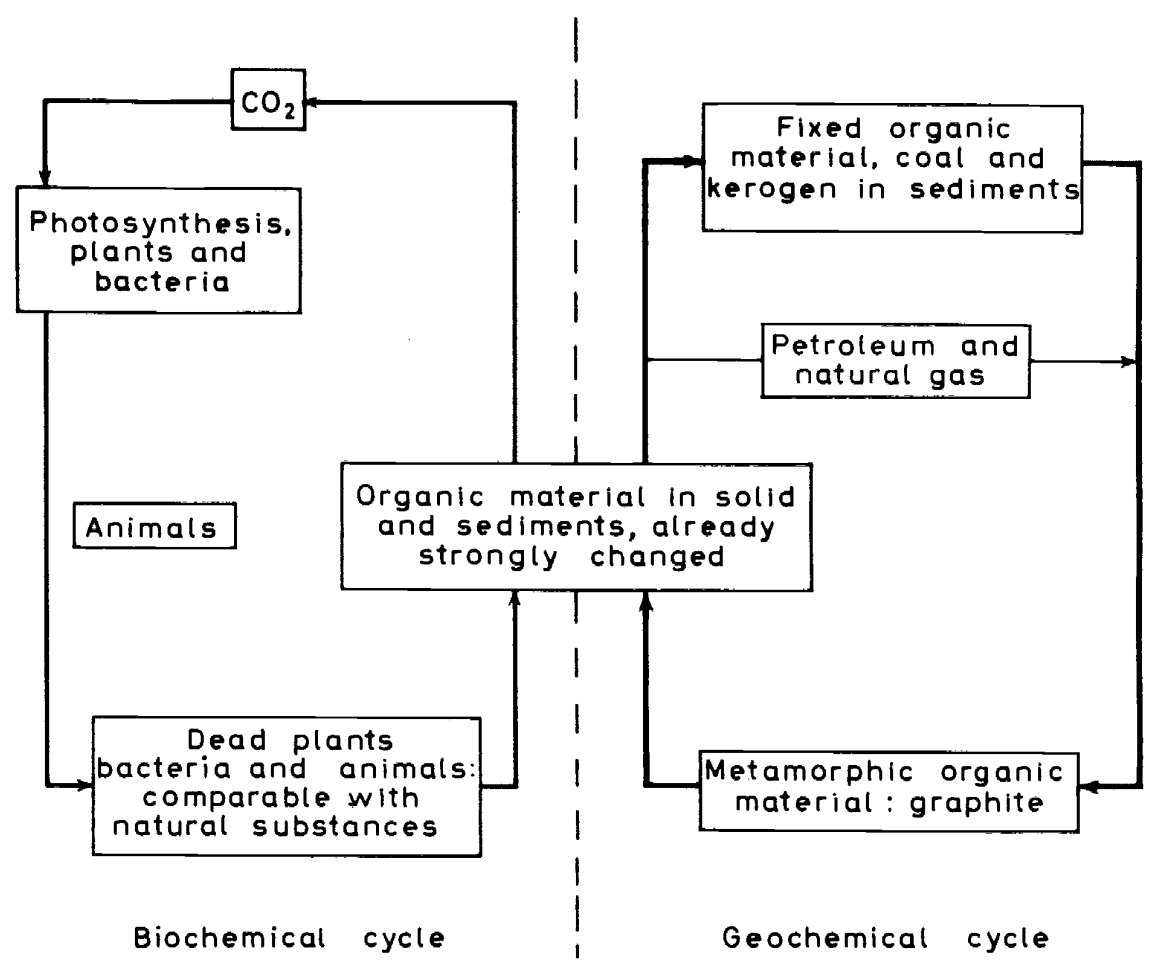

Figure 1. Carbon cycle (after ref, 2), Oxygen is present in the biochemical cycle, but not in the geochemical.

\section{THE NATURE OF SEDIMENTARY ORGANIC MATTER}

The organic matter present in sediments shows one constant characteristic: its complexity. It is chemically nearly homogeneous only in two extreme cases, that of methane, the major constituent of most natural gas, and carbon, the end product of evolution of coals, in graphite and anthracite. But petroleums, the most studied of all organic deposits, have yielded hundreds of hydrocarbons, heterocyclic substances, acids, etc. Such complexity is characteristic of practically all sedimentary organic matter. Coals present another characteristic, which they share with most sedimentary organic matter: they are essentially composed of condensed organic substances, insoluble in any solvent combination, and not amenable to structural studies in the usual sense. In sediments, some 80 to 90 per cent of the organic matter present is in fact an insoluble condensate, called kerogen, which can be isolated by dissolving the mineral matrix in hydrofluoric acid.

The usual form of sedimentary organic matter is thus complex, mostly insoluble, but it is also dispersed: less than two per cent usually, with higher concentrations only exceptionally found, e.g. in oil shales. 


\section{THE NATURE OF THE ORGANIC GEOCHEMICAL METHODOLOGY}

These characteristics explain the difficulties met by workers in this field. Analytical methods are taxed to their limit of separating power and sensitivity (e.g. capillary columns, gas-chromatography combined with massspectrometry), extreme precautions must be taken against contamination, and special degradation methods must be used to try and solubilize fragments of kerogen molecules to allow them to be studied.

This is of course the most elementary level of study of sedimentary organic matter: the gathering of reliable data. Most laboratories in the field have put to good use the experience gained in their first attempts, when they isolated what were obviously contaminants. In our case, it was one of the global pollutants: a mixture of polychlorodiphenyls!

A second level of study is that of the geochemical transformations accompanying ageing of the sediments. This is a most important field, as it may for example include attempts at explaining the processes which have led to accumulations of petroleum or natural gas.

The third, highest, level of study would be aiming at a reconstruction of the conditions prevailing at the time of sedimentation, by considering the organic molecules isolated as 'chemical fossils'. Their structure is then considered as a message, distorted by the millions of years elapsed, but maybe decipherable in terms of paleo-taxonomy (what species produced it?), of paleo-biochemistry (what was its metabolism?), or of paleo-ecology (which were the dominating species there at that time?). It is of course at this, third, level that questions have to be asked about the age of life on earth, and about the chemical activities of the early living organisms.

A complete scientific approach links the three levels of study into an integrated interpretation, and submits it to the test of rigorous experimentation.

\section{THE IMPORTANCE OF FOSSIL ISOPRENOIDS}

The field of competence of any laboratory influences of course its favoured field of study. In Strasbourg, we have so far concentrated our efforts on the sedimentary lipids: straight-chain or branched hydrocarbons, acids or esters ${ }^{4}$, polycyclic hydrocarbons, alcohols or ketones. The most informative results have been obtained with acyclic and polycyclic isoprenoids.

Fossil isoprenoids (or rather, isoprenoid-like substances, as they may not be only $\mathrm{C}_{5 n}$ substances) comprise some substances obviously preserved with no change whatsoever since the time of their inclusion in the sediments, and representing therefore messages kept intact over millions of years. The isolation of friedelin (I), isoarborinol (II) and arborinone (III) from the 50 million year old oil shales of Messel and/or Bouxwiller can only mean that these substances were present as such in plants living there and then ${ }^{5}$. This tells us something, however vague, about the mildness of the geological conditions having prevailed for all this time, as they have allowed molecules to survive despite the presence of acid-sensitive, of oxygen-sensitive, of base-sensitive groups. 


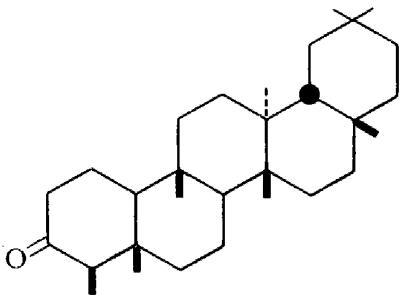

(I)

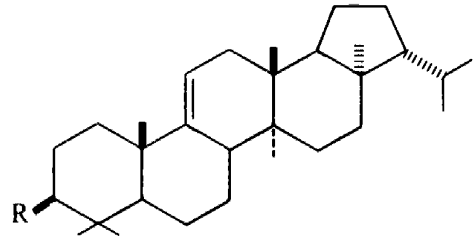

(II) $\mathrm{R}=-\mathrm{OH}$

(III) $\mathrm{R}==\mathrm{O}$

Now, at the third level of study, what can we derive from the knowledge of these molecules? Friedelin is an ubiquitous component of plant cuticles, and as such has little specific information to transmit. The arborane derivatives (II) and (III) on the contrary have only been found so far in a few tropical plants; their isolation in sediments of a lake known to be tropical by fossils of crocodiles, for example, must mean that one at least of the plants present must have been an efficient producer of these substances. What this plant was is not yet known: here we have an intact message, with a high information intensity, but coming from an undeciphered sender. It is like having read one letter, intact, on a buried manuscript. If this letter is $e$, it only shows the message to be in one of the Western languages; this is similar to the case of friedelin. If this letter is $\dot{a}$, then it must come from a much narrower group of languages, e.g. from French, but maybe also from Italian, or maybe from a forgotten idiom: this is similar to the case of arborinone, which may come from a Gramineae, or from a Moraceae... or ..., but not from any plant.

\section{Modified isoprenoids}

A much more complex problem is presented by biological markers formed, not of obviously intact molecules, but of probably modified ones. A few examples follow.

From Messel and/or Bouxwiller, we have also isolated 4-methyl-stanols (IV), -stanones (V) and -steranes (VI). These are certainly derived from living organisms. From our present knowledge of sterols in plants and animals, one is tempted to consider them as representing relics of what were originally unsaturated alcohols, modified over the ages by more or less complete reduction. Yet, it is strange that 4-methyl sterols have survived or are still recognizable in 4-methyl steranes, but that sterols, normally much

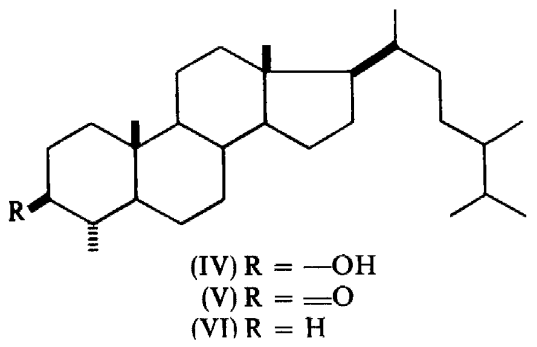




\section{SAMSARA OF ORGANIC CARBON}

more abundant, are hardly detectable in the same sediments. Furthermore, the inescapable assumption of potential reduction to saturated hydrocarbons could lead one to expect the presence of friedelane (from friedelin) and arborane (from arborinone and isoarborinol). These triterpanes are hardly detectable, if at all ${ }^{6}$.

We feel this absence may also have the value of a message to be deciphered.

Clues as to the nature of this message come from the study of the saturated isoprenoid-like hydrocarbons of the same shales. These contain very complex mixtures, dominated by $\mathrm{C}_{15}, \mathrm{C}_{16}, \mathrm{C}_{18}, \mathrm{C}_{19}$ and $\mathrm{C}_{20}$ isoprenoid-like hydrocarbons (Figure 2), but comprising also much heavier fractions ${ }^{7}$. Lycopane (VIII), $\mathrm{C}_{40} \mathrm{H}_{82}$, is most certainly a product of hydrogenation of lycopene, unless it is also a natural substance, overlooked so far in living organisms because of its inertness and low volatility. The same is true of $\beta$-carotane, isolated from another lacustrine sediment, the North American Green River shale.<smiles>CC(C)CCCC(C)CCCC(C)CCCC(C)CCCCC(C)CCCC(C)CCCC(C)CCCC(C)C</smiles>

(VIII)

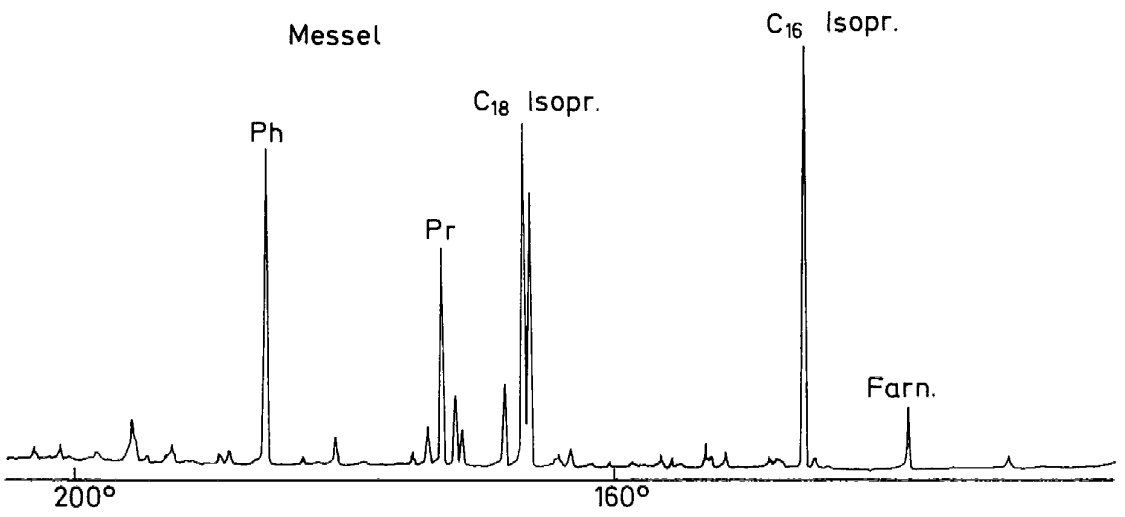

Bouxwiller

$C_{16}$ Isopr.

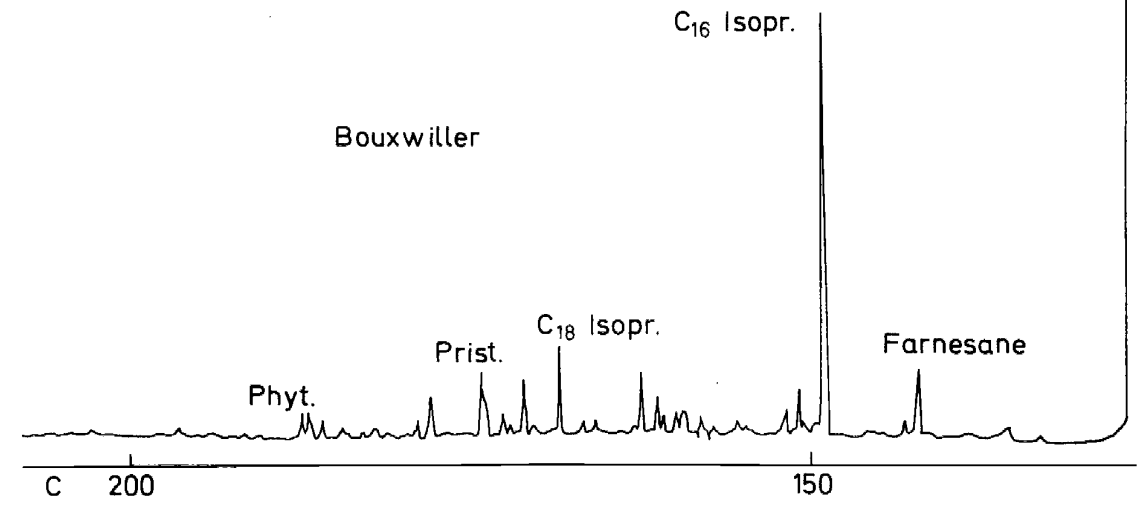

Figure 2. Gas chromatogram (capillary column) of lower molecular weight range of alkanes from the Messel and Bouxwiller shales (Eocene). Pr, Prist $=$ pristane; Ph or Phyt $=$ phytane. 
The lower acyclic $\mathrm{C}_{15}$ to $\mathrm{C}_{20}$ hydrocarbons may be derived from precursors such as lycopane or, as has generally been assumed, from phytol, a constituent of chlorophyll,

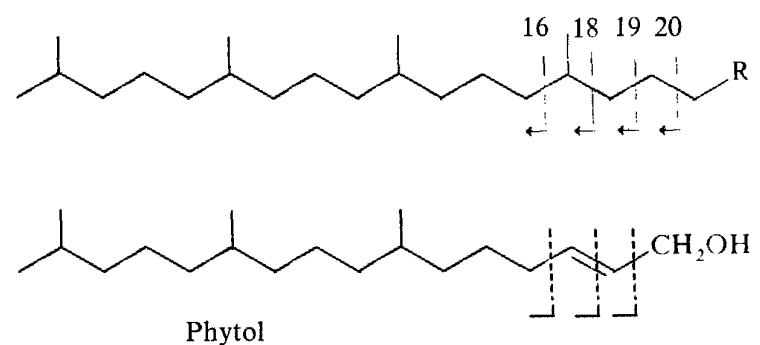

Reality may be more complex, as trace amounts of higher isoprenoid hydrocarbons, $\mathrm{C}_{21}$ to $\mathrm{C}_{25}$, have been isolated in another sediment. The highest one of this series is derived from the regular isoprenoid geranylfarnesane, and cannot come from lycopane by cleavage ${ }^{8}$. It may come from a regular polyprenol. This is another case of an undeciphered message, but not a noisy one.

\section{Pentacyclic triterpanes}

Acyclic polyterpene hydrocarbons are accompanied by pentacyclic triterpene hydrocarbons, and by their proximate lower and higher homologues, from $\mathrm{C}_{27}$ to $\mathrm{C}_{32}$ with the notable exception of $\mathrm{C}_{28}$.

In Messel and Bouxwiller, these triterpanes comprise hopane (IX) ${ }^{9}$, and the MS-fragmentation of its companions suggests them to be nor- and homohopanes $(\mathrm{X})$. This has been confirmed by synthesis.<smiles>[Y2]=CCC(C)C1CCC2(C)C1CCC1(C)C2CCC2C3(C)CCCC(C)(C)C3CCC21C</smiles>

Nor-hopanes could conceivably arise by $\mathrm{C}-\mathrm{C}$ bond cleavage of hopane, but homohopanes present a very interesting problem, which is at the centre of our present studies. No homo-triterpene of the pentacyclic series is known in Nature, and the presence in petroleum of other homo-triterpanes ${ }^{10}$ suggests we are dealing here with a significant phenomenon, any explanation of which must include the fact that no 3-hydroxy hopane derivative, and no 3-desoxyfriedelane and arborane, is present in any significant amount in Messel and Bouxwiller. 


\section{An explanation (hypothetical)}

Our present interpretation of the various facts mentioned can be summarized as follows:

(1) The absence of arborane or friedelane is taken to mean that 3-oxygenated triterpenes have not been efficiently reduced in our sediments-and therefore to mean that hopane and its companions come from 3-desoxy triterpenes.

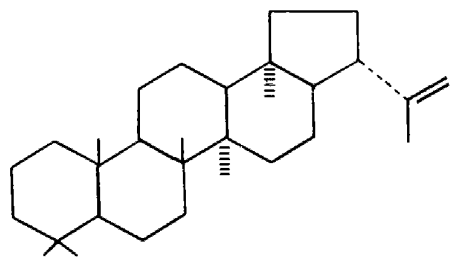

(XI)

(2) Diploptene (XI) [22(29)-hopene] is such a triterpene, first isolated from ferns, but now recognized as a widespread constituent of microorganisms such as blue-green algae and other procaryots ${ }^{11}$. We assume that hopane derivatives, in our sediments, are of procaryotic origin. Thus, 3hydroxy and 3-keto triterpenes would be intact chemical fossils derived from higher plants, but hopane derivatives would be modified chemical fossils due to paleo-microbiological decomposition of higher organisms during the first stages of sedimentation: they would imply an intense procaryotic activity, to give chemical traces of the procaryots.

(3) Procaryots producing diplotene contain little or no sterols, but do contain 4-methyl sterols ${ }^{11}$. These may be potential unsaturated precursors of the 4-methyl stanols from Messel and/or Bouxwiller. This strange preponderance of 4-methyl derivatives may therefore be indicative of a procaryotic process.

(4) The following processes may explain the origin of the nor- and homohopanes apparentiy present:

(i) Kerogen would be formed in particular by polycondensation of functional precursors, by ionic or radical $\mathrm{C}-\mathrm{O}-\mathrm{C}$ or $\mathrm{C}-\mathrm{C}$ bond formation. In particular, any double-bond of the type $-\mathrm{C}=\mathrm{CH}_{2}$ could, by radical coupling

give part systems $-\underset{\mid}{\mathrm{C}}-\mathrm{CH}_{2}-\mathrm{C}-$.

(ii) This process could be reversed, by radical $\mathrm{C}-\mathrm{C}$ cleavage either of the same bond (leading to $-\mathrm{C}=\mathrm{CH}_{2}$ and to $-\mathrm{CH}-\mathrm{CH}_{3}$ ), or of another bond. This would then lead, from diploptene, to unsaturated hydrocarbons (reentering kerogen), and to trisnor-, not bisnor-, hopanes and homo-, bishomo- hopanes, etc. Nor-hopanes would have left $\mathrm{C}$-atoms in the kerogen Homo-hopanes would have taken $\mathrm{C}$-atoms from the kerogen. Their formation from diploptene would be accompanied by progressive dehydrogenation of the kerogen ${ }^{12}$.

Any molecule not yet fully saturated would have little chance of surviving 


\section{G. OURISSON}

(cf. the absence of olefins in petroleum), but would be recaptured by the kerogen. Any saturated hydrocarbon on the other hand would have attained a state of total renouncement of any bonding - a state of nirvana-and would be kept unchanged for a very long time indeed.

The main obstacle for a direct test of these hypotheses rests with the impossibility of experimenting under geological conditions!

\section{ACKNOWLEDGEMENTS}

Dr P. Albrecht, MM P. Arpino, Chr. Spyckerelle and A. van Dorselaer have devoted their full activity to our programme. Drs R. Brandt and H. Knoche have taken part in the first stages. The Bristol group of Dr G. Eglinton has helped us by constant reciprocal contacts.

Our initial launching of research in this field owes a lot to the acute perspicacity of geological friends, Professors G. Millot and J. Lucas. From the Department of Geology, Professor G. Dunoyer de Segonzac and Drs C. Sittler and M. Schuler have helped us in a one-way collaboration, very rewarding to us.

Our investigations were carried out as part of research programme DGRST No. 64-FR-058, and helped by various organizations, including CNRS and ERAP.

\section{REFERENCES}

1 J. R. Maxwell, C. T. Pillinger and G. Eglinton, Quart. Rev. Chem. Soc., 25, 571 (1971).

${ }^{2}$ P. Albrecht and G. Ourisson, Angew. Chem. (Internat. Ed. Engl.), 10, 209 (1971).

3 a Advances in Organic Geochemistry, a series of yearly monographs, Pergamon Press.

${ }^{b}$ Organic Geochemistry; Methods and Results, ed. G. Eglinton and Sister M. T. J. Murphy, Springer: Heidelberg (1969).

${ }^{4}$ P. Arpino, P. Albrecht and G. Ourisson, C.R. Acad. Sci., Paris, 270, 1760 (1970).

5 P. Albrecht and G. Ourisson, Science, 163, 1192 (1969).

${ }^{6}$ Unpublished observations made in Strasbourg (P. Albrecht, P. Arpino) and in Bristol (J. R. Maxwell, B. J. Kimble).

7 P. Arpino, P. Albrecht and G. Ourisson, Proceedings of the Fifth International Meeting on Organic Geochemistry, Hanover, Germany, (September 1971).

${ }^{8} \mathrm{Chr}$. Spyckerelle and P. Arpino, unpublished observations.

9 J. R. Maxwell and B. J. Kimble, unpublished observations.

10 I. R. Hills and E. V. Whitehead, Nature, Lond., 209, 977 (1966).

11 C. W. Bird, J. M. Lynch, F. J. Pirt and W. W. Reid, Nature, Lond., 230, 473 (1971). c.f. also E. V. Whitehead, Chem. \& Ind., 1116 (1971) and M. de Rosa, A. Gambacorta, L. Minale and J. D. Bu'Lock, Chem. Commun., 619 (1971).

12 Similar sequences have been postulated by M. Blumer, in particular for porphyrins. 